\title{
A centralidade do pensamento de William Appleman Williams no debate historiográfico sobre a Guerra Fria
}

\author{
The centrality of William Appleman William's \\ thinking in the historiographical debate on the Cold War
}

Flávio Combat*

Resumo: William Appleman Williams foi o primeiro historiador norteamericano a defender, no intenso debate historiográfico pela redefinição de uma memória sobre a Guerra Fria, uma interpretação distinta daquela sustentada pelos autores ortodoxos sobre a origem e as consequências desse conflito. Williams não apenas desafiou as teses da ortodoxia, mas também propôs uma interpretação singular da sociedade norte-americana e de seus interesses representados na política externa conduzida pelos EUA desde o final do século XIX. O objetivo central do artigo é analisar, da perspectiva historiográfica, as teses desenvolvidas por Williams, sobretudo no livro "The Tragedy of American Diplomacy" (1959), obra central que sintetizou as suas conclusões sobre a origem do expansionismo norte-americano e sobre a sua centralidade na definição da política externa conduzida pelos EUA a partir do final do século XIX. A análise retoma a tese da fronteira ("frontier thesis"), que, na interpretação de Williams, é o fundamento da política externa primordialmente expansionista conduzida pelos Estados Unidos no período em observação. Nesse sentido, são analisadas importantes iniciativas de política externa tomadas pelos Estados Unidos entre o começo do século XX e o final da Segunda Guerra Mundial, sustentando a estreita relação entre a "política de portas abertas" ("open doors policy") e o objetivo primordial de tornar o mundo seguro e aberto para os interesses norte-americanos. Por fim, o texto analisa a tese de Williams de que a "tragédia" da diplomacia norte-americana 
no século XX decorreu precisamente da introjeção da "tese da fronteira" na política externa dos Estados Unidos.

Palavras-chave: Guerra Fria; Historiografia; Revisionismo; Open Door Policy; Tese da Fronteira

Abstract: William Appleman Williams was the first American historian to defend, in the intense historiographical debate for redefining a memory on the Cold War, a different interpretation from that sustained by Orthodox writers on the origins and consequences of that conflict. Williams not only challenged the orthodoxy theses, but also proposed a singular interpretation of the American society and its interests represented in the foreign policy conducted by the US since the late nineteenth century. The central objective of this article is to analyze, from a historiographical perspective, the thesis developed by Williams, especially in the book "The Tragedy of American Diplomacy" (1959), a masterpiece that summarized his findings on US expansionism origins and on its centrality in shaping the foreign policy conducted by the US from the late nineteenth century. The analysis takes up the "frontier thesis", which, in Williams' interpretation, is the foundation of the primarily expansionist foreign policy conducted by the United States in the period under observation. In this sense, important foreign policy initiatives taken by the United States between the early twentieth century and the end of World War II are analyzed, supporting the close relationship between the "open doors policy" and the essential aim to make the world safe and open for the American interests. Finally, the text analyzes Williams' thesis that the "tragedy" of US diplomacy in the twentieth century took place precisely owing to the introjection of "frontier thesis" in US foreign policy.

Keywords: Cold War; Historiography; Revisionism; Open Door Policy; Frontier Thesis

*Professor Adjunto da Universidade Federal do Rio de Janeiro, no curso de Defesa e Gestão Estratégica Internacional (DGEI - UFRJ). Economista (UFF), Mestre e Doutor em História Comparada (PPGHC - UFRJ). Email: facombat@gmail.com 


\section{Introdução}

Na década de 1960, o envolvimento dos Estados Unidos na Guerra da Indochina aprofundou as críticas aos objetivos declarados pela Casa Branca com a política de contenção do comunismo. A corrente historiográfica revisionista, principal abordagem crítica que contestou as teses da ortodoxia ${ }^{1}$, ganhou projeção exatamente no contexto da intervenção norte-americana no Sudeste Asiático, que marcou um período de amplo questionamento do papel dos Estados Unidos na política internacional. Dentre os representantes do revisionismo ${ }^{2}$ norte-americano, William Appleman Williams destacou-se como o primeiro autor a questionar establishment historiográfico e intelectual que procurava explicar e legitimar a política externa dos Estados Unidos durante a Guerra Fria.

Os historiadores revisionistas propunham uma interpretação sobre a Guerra Fria, a sua origem e os seus desdobramentos, radicada numa nova visão de mundo e numa compreensão distinta sobre o papel exercido pelos Estados Unidos. Cabe, contudo, observar que a crítica revisionista não se limitava à política externa norte-americana. Ela também colocava em questionamento a própria organização social dos Estados Unidos, criticando principalmente a centralidade do expansionismo econômico e político para o modelo norteamericano de capitalismo.

O objetivo central do artigo é analisar, da perspectiva do debate historiográfico, as teses seminais desenvolvidas por William Appleman Williams na obra The Tragedy of American Diplomacy (1959) ${ }^{3}$, com destaque para as suas conclusões sobre a origem do expansionismo norte-americano e sobre a sua centralidade na definição da política externa conduzida pelos Estados Unidos a partir do final do século XIX.

O texto está dividido em três seções. Na primeira, analiso a relação, proposta por Williams, entre a tese da fronteira (frontier thesis) e o expansionismo da política externa norte-americana. Nesse sentido, a "política de portas abertas" é analisada como um pilar para a projeção, em escala mundial, dos interesses norte-americanos a partir do final do século XIX. Na segunda seção, analiso algumas consequências da "open doors policy" para o processo de cristalização dos antagonismos entre os Estados Unidos e a União Soviética, ao longo da Segunda Guerra Mundial. Pretende-se, dessa forma, analisar a tese revisionista de que a política externa expansionista norte-americana teve papel central na consolidação da Guerra Fria. A última seção apresenta a tese mais polêmica de Williams: a proposição de que a verdadeira "tragédia" da diplomacia norte-americana no século XX decorreu precisamente da introjeção da "tese da fronteira" na política externa dos Estados Unidos. 


\section{A "Tese da Fronteira": fundamentos do expansionismo norte- americano na interpretação de W. A. Williams}

A interpretação sobre a política externa norte-americana apresentada por William Appleman Williams em sua obra principal, The Tragedy of American Diplomacy (1959), é a conclusão de uma extensa análise sobre os fundamentos históricos e os interesses que balizaram as decisões tomadas por Washington, sobretudo a partir do final do século XIX. Assim, avalio que, para entender as conclusões apresentadas em The Tragedy, é primordial retomar a análise de Williams sobre os fundamentos do expansionismo norte-americano e sobre as ideias nas quais a política externa dos Estados Unidos, desde o final do século XIX, estava assentada.

Num artigo publicado em 1955 (quatro anos antes da publicação de The Tragedy), intitulado The frontier thesis and American foreign policy, Williams analisou detidamente o que considerava a base ideológica da política externa norte-americana conduzida entre o fim do século XIX e a década de 1950 (tomando por base, claramente, o período em que o texto foi escrito, o que impediria a extensão da lógica observada até então para o período de toda a Guerra Fria). Segundo o autor, a "tese da fronteira" ("frontier thesis") era o fundamento da política externa primordialmente expansionista conduzida pelos Estados Unidos no período em observação.

Williams sustentou que a "tese da fronteira" consolidada e amplamente difundida ao final do século XIX remontava ao trabalho de dois historiadores norte-americanos (Frederick Jackson Turner e Brooks Adams) que exerceram grande influência sobre os governos dos presidentes Theodore Roosevelt $\mathrm{e}$ Woodrow Wilson. As ideias propostas por Turner e Adams na década de 1890 "se tornaram a visão de mundo de gerações subsequentes de norte-americanos (...) e são importantes para compreender a expansão imperial dos Estados Unidos no século XX” (WILLIAMS, 1955, p. 89).

Williams sintetizou as concepções de Turner e de Adams sobre a "tese da fronteira" e estabeleceu uma complementaridade entre elas no que se refere à influência sobre a política externa norte-americana. Segundo o autor:

Uma ideia é o conceito de Frederick Jackson Turner de que a verdadeira e única democracia dos Estados Unidos foi o produto de uma fronteira em expansão. A outra ideia é a tese de Brooks Adams de que a verdadeira e única democracia dos Estados Unidos só poderia ser preservada por meio de uma política externa expansionista. A ideia de Turner foi concebida para explicar uma experiência já encerrada [a formação da democracia norte-americana] e para alertar sobre os perigos à frente. A ideia de Adams foi calculada para preservar no presente a meia verdade proposta por Turner sobre o passado e para projetá-la no futuro. (...) Mas 
tomadas em conjunto, as ideias de Turner e Adams proveram aos construtores de impérios norte-americanos uma visão e uma explicação sobre o mundo, e um programa de ação razoavelmente específico de 1893 a 1953. (WILLIAMS, 1955 , p. 90, tradução do autor)

Portanto, na interpretação proposta por Williams, a "tese da fronteira", que orientou os EUA a partir do final do século XIX, se refere à combinação de duas ideias: (i) a democracia norte-americana nasceu da expansão das fronteiras dos Estados Unidos (em referência à expansão territorial para o Oeste), tal como proposto por Turner; (ii) e a reprodução dessa democracia dependia de uma política externa expansionista, em linha com o proposto por Adams.

O sucesso e a projeção das ideias de Turner e de Adams devem ser analisados no contexto em que foram apresentados à sociedade norte-americana. $\mathrm{Na}$ virada do século XIX para o século XX, os Estados Unidos estavam mergulhados numa Grande Depressão, que sucedera três décadas de rápido crescimento econômico e de expressiva concentração do capital. Ao caracterizar a situação dos Estados Unidos naquele período, Williams ressaltou:

A sociedade norte-americana havia passado, no espaço de uma geração, por uma revolução econômica em cada uma de quatro áreas críticas: na [introdução da] máquina a vapor, [na produção de] aço, nas comunicações e na agricultura. (...) A indústria básica de aço e o sistema de transporte do país estavam completos. A taxa de crescimento econômico nacional estava declinando. Novos avanços tecnológicos ainda estavam por ser aplicados por todos os lados. Em vez disso, parecia que os gigantes da comunidade econômica haviam se desviado [do objetivo de] conquistar a natureza para despojar os seus pares. Trustes, holdings e corporações começaram a devorar os empresários individuais num banquete de consolidação e concentração. A agricultura estava deixando de ser um negócio familiar. (...) O Census Director [um órgão do Departamento do Comércio] enfatizou o mau presságio quando anunciou, em abril de 1891, que "dificilmente poderia ser afirmado que havia uma fronteira" [nova para a expansão do capital]. (...) Os trabalhadores não estavam mais felizes. A taxa relativa de aumento dos salários reais despencou, e então, de 1889 a 1898, os salários foram reduzidos em termos absolutos. "Greve!" se transformou num grito de guerra. (WILLIAMS, 1955, p. 91-92, tradução do autor)

Como observado por Williams, na virada do século XIX para o século XX, o crescimento econômico dos Estados Unidos exibia sinais claros de 
esgotamento, impondo limites à capacidade de expansão do capital. Se, como propunha Turner, a experiência norte-americana na construção da democracia tinha sido baseada na bem-sucedida expansão das fronteiras territoriais estadunidenses para o Oeste, então a solução para os problemas enfrentados pela economia norte-americana em 1890 poderia, como defendia Adams, estar relacionada à expansão internacional das fronteiras econômicas dos Estados Unidos. O mundo, em síntese, seria a "nova fronteira Oeste" dos Estados Unidos.

Williams ressaltou que Turner, assim como Adams, compartilhava a ideia de que a competição entre indivíduos, orientados por interesses econômicos, era a chave da democracia norte-americana. Portanto, a busca e a competição pregressas por novas oportunidades econômicas na fronteira Oeste dos Estados Unidos haviam lançado a base da própria democracia norteamericana. Contudo, ao final do século XIX, quando todas as fronteiras da nação já haviam sido alcançadas, a salutar competição entre indivíduos cedeu lugar à predação do capital pelo capital, sufocando o espírito da própria democracia norte-americana.

A expansão da fronteira econômica norte-americana para além dos limites nacionais dependia de uma política externa em sintonia com as teses propostas por Turner e por Adams. A natureza do expansionismo sintetizada na interpretação dos dois historiadores era especialmente útil e facilmente incorporável no discurso político que se fortalecia nos Estados Unidos do final do século XIX. A crise econômica exigia respostas inequívocas aos problemas que se apresentavam dentro da sociedade norte-americana. Que solução para a crise seria melhor do que aquela já experimentada pelos Estados Unidos em sua bem-sucedida consolidação como uma nação? As ideias de Adams e, em especial, de Turner ecoaram pela sociedade norte-americana como uma faísca lançada sobre pólvora. Ao apresentar a sua própria interpretação sobre a "frontier thesis", em 1893, Turner ${ }^{5}$ destacou:

\footnotetext{
Esse permanente renascimento, essa fluidez da vida americana, essa expansão rumo ao oeste com as suas novas oportunidades, o seu contínuo contato com a simplicidade da sociedade primitiva, fornecem as forças que dominam a vida americana. (...) A expansão fomentou o individualismo que, desde o começo, fomentou a democracia. (...) [A fronteira] era uma fonte mágica da juventude na qual os Estados Unidos continuamente se banhavam e rejuvenesciam. Sem ela, fissuras entre as classes começam a abrir, fissuras que podem aumentar e se transformar em abismos. (TURNER, 1893 , p. 23, tradução do autor)
}

Expansão, individualismo e democracia: a trindade do modelo social 
norte-americano na interpretação proposta por Turner. Nos termos de Williams, Turner deu aos Estados Unidos do final do século XIX “uma visão nacionalista de mundo que aplacou as suas dúvidas, acabou com as suas confusões e justificou a sua agressividade" (WILLIAMS, 1955, p. 93). O casamento entre o individualismo econômico e a ideologia de difusão mundial da democracia era a justificativa perfeita, naquele contexto, para o expansionismo norte-americano. Das universidades aos salões da Casa Branca, das indústrias de aço aos bancos nova-iorquinos, as ideias de Turner foram aclamadas, lançando o que poderia ser considerada uma sólida base de refundação da histórica aliança entre o Estado e o capital estadunidenses - abalada, porém nunca abolida, durante a crise. Como sintetizou Williams:

A tese de Turner se tornou a explicação dos Estados Unidos para o seu sucesso e a prescrição [de uma solução] para os seus próprios problemas e os problemas dos outros. A sua interpretação da experiência americana encorajou e inspirou milhões. (...) Possivelmente Theodore Roosevelt; certamente Woodrow Wilson, e as gerações de homens de negócios e de burocratas cujos professores lhes asseguraram que uma fronteira em expansão era a causa do sucesso democrático da América. Mas primordialmente ele [Turner] foi o apóstolo de um movimento de renovação que restaurou a fé dos conquistadores da América do Norte e os transformou em cruzados internacionais. (WILLIAMS, 1955 , p. 95, tradução do autor)

Em 1893, no mesmo ano em que as ideias de Turner foram lançadas, Brooks Adams chegou a conclusões semelhantes. Dois anos depois, em The law of civilization and decay ${ }^{6}$, Adams apresentou a sua própria interpretação sobre a "frontier thesis". Porém, ao contrário de Turner, que centrara a sua análise na expansão das fronteiras nacionais estadunidenses, Adams propôs uma "tese da fronteira" para o mundo, argumentando que "os centros da civilização mundial seguiram as fronteiras da riqueza econômica e da oportunidade rumo ao oeste ao redor do mundo". O caminho de expansão da fronteira da chamada "civilização" era, para Adams, muito claro: "[partia] do Mar Mediterrâneo, [passava] pela Europa Ocidental e [chegava] à Grã-Bretanha” (WILLLIAMS, 1955, p. 94).

Williams argumentou que as ideias de Adams floresceram, sobretudo, após a Segunda Guerra Mundial, ao embasar o mais célebre idealizador da política externa dos Estados Unidos naquele período: George Frost Kennan. Ao explicar e defender a política de contenção do comunismo, Kennan citava Adams como um dos poucos pensadores norte-americanos a entender os fundamentos verdadeiramente adequados à política externa dos Estados 
Unidos ${ }^{7}$. Williams concluiu que a Doutrina de Contenção do Comunismo e a sua expressão prática, a Doutrina Truman, foram exemplos da clássica combinação entre as interpretações de Turner e de Adams sobre a "frontier thesis". Assim, sumarizou Williams:

\begin{abstract}
A Doutrina Truman parecia quase uma afirmação clássica da tese de que a segurança e o bem-estar dos Estados Unidos dependiam do sucesso da execução da missão singular da América de defender e estender a fronteira da democracia por todo o mundo. (...) essas características eram sintetizadas no conceito de uma economia em expansão, que se tornou o novo credo norte-americano nos anos posteriores a $1935 \mathrm{e}$ particularmente durante a Guerra Fria. (WILLIAMS, 1955, p. 101, tradução do autor)
\end{abstract}

Na perspectiva proposta por Williams, a Doutrina Truman evocava a defesa da democracia como a principal bandeira da política externa dos Estados Unidos após a Segunda Guerra Mundial. Williams observou que a qualificação de determinadas teorias como "democráticas" tornou-se prática comum durante a Guerra Fria se essa caracterização se mostrasse útil ao expansionismo dos Estados Unidos, conformando uma espécie de "padrão imperialista de julgamento" das ideias mais convenientes a Washington (WILLIAMS, 1995, p. 101). Não por outra razão, a Doutrina Truman foi recorrentemente evocada ao longo de toda a Guerra Fria como um estandarte da luta pela expansão da democracia, servindo a sucessivos governos norte-americanos que tinham de justificar uma política externa que muitas vezes beirava a barbárie.

Algumas conclusões podem ser extraídas da interpretação de Williams sobre o papel da "frontier thesis" na política externa conduzida pelos Estados Unidos entre o final do século XIX e a primeira metade do século XX. A primeira delas é a centralidade da "tese da fronteira" na interpretação revisionista sobre a origem das tensões entre os Estados Unidos e outros países (em especial, a Rússia e, após 1922, a União Soviética). Na medida em que uma fronteira em expansão se consolidou como o alicerce central da política externa norteamericana, uma série de conflitos com os interesses coloniais e imperialistas de outros países pontuaram a história dos Estados Unidos a partir do final do século XIX. O adensamento desses conflitos, no decurso da reafirmação da Open Door Policy durante e após a Segunda Guerra Mundial, guarda, como propõe Williams, um dos fundamentos da Guerra Fria.

Em segundo lugar, ao analisar a consolidação da "frontier thesis" como o norteador da diplomacia norte-americana na primeira metade do século XX, Williams lançou as bases da interpretação revisionista sobre a linhagem em comum entre a Open Door Policy, o New Deal, a Política da Boa Vizinhança, a Doutrina de Contenção do Comunismo, a Doutrina Truman e o Plano Marshall, 
todos radicados, de acordo com essa interpretação historiográfica, na defesa de uma política externa essencialmente expansionista.

Por fim, as conclusões de Williams sobre a incorporação da "frontier thesis" na política externa norte-americana são, como se pretende demonstrar, a base de sua interpretação desenvolvida em The Tragedy of American Diplomacy, onde o autor concluiu que a verdadeira "tragédia" da diplomacia norte-americana no século XX decorreu precisamente da introjeção da "tese da fronteira" na política externa dos Estados Unidos.

\section{Da Open Door Policy à Guerra Fria: a cristalização dos antagonismos entre os Estados Unidos e a União Soviética na década de 1940}

Em The Tragedy of American Diplomacy, Williams sustentou que a Open Door Policy, vigorosamente defendida pela política externa conduzida por Washington entre o final do século XIX e a primeira metade do século $\mathrm{XX}$, foi a principal estratégia dos Estados Unidos para expandir a sua fronteira econômica pelo mundo. Assim, a "tese da fronteira" proposta por Frederick Turner e Brooks Adams proveu os fundamentos ideológicos para uma política externa assentada na ideia de que a expansão era não apenas a saída para os problemas econômicos conjunturais dos Estados Unidos, mas a própria solução para a bem-sucedida reprodução, em escala mundial, do modelo democrático estadunidense. Essa perspectiva desempenhou, segundo Williams, papel central na guerra contra a Espanha em 1898 e nas diversas políticas conduzidas nos anos seguintes para conquistar mercados na Ásia.

Orientada pelo princípio da Open Door Policy, a política externa norte-americana projetou internacionalmente os interesses e o poder dos Estados Unidos, mas também "engendrou os antagonismos criados por todos os impérios" (WILLIAMS, 1959, p. 125), impondo grandes desafios à diplomacia norte-americana. É exatamente com base nessa interpretação que Williams identificou uma continuidade entre a Guerra Hispano-Americana de 1898, a Open Door Policy (século XIX) e o New Deal (1933-1936): todas essas iniciativas de política externa foram norteadas pelo objetivo central de garantir a expansão da fronteira econômica norte-americana.

A interpretação historiográfica defendida por Williams foi empregada de forma ainda mais profícua para analisar a relação entre a política externa expansionista norte-americana e a cristalização dos antagonismos entre Washington e Moscou que estão, segundo o Revisionismo, na origem da Guerra Fria. Esta seção será dedicada à análise dessa relação, em linha com as ideias da corrente historiográfica revisionista.

Todos os capítulos de The Tragedy of American Diplomacy são iniciados com citações que ilustram o ponto de vista daqueles que estavam diretamente envolvidos com os problemas da diplomacia norte-americana nos períodos 
analisados por Williams. Essa é, aliás, uma marca distintiva dos seus textos. Uma citação, em especial, destacada na abertura do sexto capítulo de The Tragedy, é bastante elucidativa.

A situação no mundo hoje [1948] não é primordialmente o resultado das dificuldades naturais que sucedem uma grande guerra. Ela é principalmente o resultado do fato de que uma nação não apenas se recusou a cooperar com o estabelecimento de uma paz justa e honrosa, mas - ainda pior - na verdade procurou evitá-la. (TRUMAN, 1948 apud WILLIAMS, 1959, p. 204, tradução do autor)

A ênfase do presidente Truman na culpa da União Soviética pelos atritos com os Estados Unidos após a Segunda Guerra Mundial era certamente expressão de uma visão muito difundida na sociedade norte-americana sobre a origem e a causa dos conflitos entre Washington e Moscou. Para Williams, ao sustentar a necessidade de um amplo programa de assistência econômica e militar para restaurar a Europa e evitar a disseminação da influência comunista, Truman defendia não somente a essência do Plano Marshall, mas professava a sua crença na Open Door Policy.

Williams defendeu que o envolvimento dos Estados Unidos na Segunda Guerra Mundial não alterou a essência da política externa norte-americana conduzida desde o final do século XIX, sustentada pela crença na necessidade de expansão da fronteira econômica dos Estados Unidos como o principal - senão único - meio para assegurar a reprodução da prosperidade e da democracia estadunidenses. Ao final da Segunda Guerra, e mesmo antes do envolvimento norte-americano no conflito, a centralidade do Open Door Policy era mais premente do que nunca. A memória dos anos da Grande Crise da década de 1930 ainda estava viva quando a vitória sobre os nazistas já era tida como certa. Citando Dean Achenson, num discurso de 1944, Williams observou:

Não podemos passar por outros dez anos [de depressão] como os dez anos ao final da década de 1920 e o começo da década de 1930, sem sentir as mais terríveis consequências sobre os nossos sistemas econômico e social. Nós aprendemos que aquilo que o país produz é utilizado e vendido com base em acordos financeiros que tornam a sua produção possível. A minha argumentação é que não podemos assegurar o pleno emprego e a prosperidade nos Estados Unidos sem os mercados externos. (ACHENSON, 1944 apud WILLIAMS, 1959, p. 134, tradução do autor)

Segundo Williams, a crença na Open Door Policy ecoava nos Estados Unidos com ainda mais força após 1945 por conta do diferencial 
de poder entre os Estados Unidos e as nações devastadas pela guerra. Foi precisamente num quadro em que gozavam de um imenso poder econômico e político que os Estados Unidos teriam se recusado a reconhecer os interesses e as necessidades da União Soviética após a devastadora luta contra o Terceiro Reich. Portanto, é nesse contexto de aprofundamento dos antagonismos entre Washington e Moscou que Williams explicou a "cristalização da Guerra Fria", traçando uma comparação detalhada entre a política interna e a política externa norte-americana e soviética ao longo da década de 1940.

Ao analisar os grandes desafios no caminho de Franklin D. Roosevelt no começo dos anos 1940, Williams sublinhou que o astuto presidente era capaz de reconhecer a contradição entre as contingências históricas de seu tempo e a sua crença na Open Door Policy. Assim, se, por um lado, a expansão das fronteiras econômicas era o caminho por excelência para equacionar os problemas econômicos norte-americanos, por outro, as circunstâncias impostas pela Segunda Guerra Mundial exigiam uma concertação de poder com outras nações que poderia, a princípio, impor limites à estratégia imperial dos Estados Unidos. Embora reconhecesse este dilema, Roosevelt não o resolveu e reafirmou, até o fim de seus dias, a sua confiança na Open Door Policy como o melhor caminho a ser seguido pelos Estados Unidos.

Assim como Roosevelt, os presidentes que o sucederam na Casa Branca se recusaram a reconhecer qualquer limite ao expansionismo econômico e político dos Estados Unidos, guiando a política externa norte-americana com base nos princípios da Open Door. Convencidos da necessidade de expandir internacionalmente as fronteiras dos Estados Unidos, Roosevelt e Truman "embarcaram num programa para forçar a União Soviética a aceitar a concepção tradicional dos Estados Unidos sobre si mesmos e sobre o mundo" (WILLIAMS, 1959, p. 136) e, ao fazê-lo, aprofundaram antagonismos alimentados desde o século XIX.

No começo da década de 1940, assim como os seus pares norteamericanos, os líderes soviéticos também eram confrontados pelas contingências históricas. De um lado, pesava a crença marxista-leninista na revolução mundial; de outro, a necessidade de responder aos problemas concretos que ameaçavam a ordem social interna da União Soviética. Williams propôs que, desde o começo da Segunda Guerra Mundial, Moscou reconhecia a reconstrução interna e a segurança da União Soviética como os seus interesses vitais. Porém, diante dos imperativos expansionistas da política externa norteamericana, restavam poucas alternativas concretas. Assim, sublinhou Williams:

Os líderes russos claramente reconheciam o seu dilema e concluíram que a reabilitação [econômica interna da URSS] e a segurança militar eram os pontos em relação aos quais as suas decisões tinham de ser tomadas. Mas a política norte-americana não oferecia aos russos nenhuma 
escolha real sobre essas questões [recuperação e segurança]. Particularmente depois que a bomba atômica foi criada e usada, a atitude dos Estados Unidos deixou aos soviéticos somente uma opção real: ou aquiescer as propostas norte-americanas ou serem confrontados com o poder e a hostilidade norte-americanos. Foi a decisão dos Estados Unidos de empregar o seu novo e incrível poder [a bomba atômica] para sustentar a tradicional Open Door Policy que cristalizou a Guerra Fria. (WILLIAMS, 1959, p. 136-137, tradução do autor)

É fundamental destacar que, na interpretação revisionista, o reconhecimento da Open Door Policy como um fator central para a cristalização da Guerra Fria não significa uma mera inversão da interpretação ortodoxa, na sua incansável busca por culpados pelo conflito. De acordo com Williams, a questão central é determinar qual dos lados envolvidos no conflito comprometeu o seu poder com políticas que aprofundaram antigas tensões e adotou uma política externa inflexível que exacerbou antagonismos. Nesse sentido, culpar os soviéticos pelo começo da Guerra Fria é, segundo Williams, a solução mais fácil para desonerar os Estados Unidos de suas responsabilidades pela condução da Open Door Policy.

Williams concluiu, então, que uma revisão mais profunda da política externa norte-americana e das suas consequências a partir década de 1940 dependia, inicialmente, do reconhecimento de duas questões.

Primeiro, é fundamental reconhecer que "os Estados Unidos tiveram, de 1944 até pelo menos 1962, uma vasta preponderância de poder factível e em potencial vis-à-vis à União Soviética” (WILLIAMS, 1959, p. 137). Essa supremacia sustentada por Washington desfaz, segundo Williams, qualquer argumentação de que os Estados Unidos foram forçados, pelas circunstâncias históricas ou por uma correlação de poder desfavorável aos norte-americanos, a conduzir uma determinada política externa. Williams questionou, assim, o pressuposto da ortodoxia de que a política externa norte-americana após a Segunda Guerra Mundial era primordialmente reativa, respondendo às iniciativas expansionistas soviéticas.

Em segundo lugar, deve-se reconhecer, como sustentou Williams, que "os Estados Unidos usaram ou implementaram a sua preponderância de poder totalmente de acordo com os pressupostos e com a tradição da estratégia da Open Door Policy" (WILLIAMS, 1959, p. 138). Nesse sentido, os Estados Unidos nunca consideraram a possibilidade de estabelecer uma política externa com os soviéticos com base em princípios diferentes daqueles sintetizados pela Open Door, o que ajuda a explicar o pequeno esforço empenhado para alcançar qualquer modus vivendi permanente com a União Soviética após a Segunda Guerra Mundial. 
Williams argumentou que, para alguns autores, os Estados Unidos estenderam a mão aos soviéticos no imediato pós-guerra ao oferecer a Moscou a possibilidade de assistência econômica. Para Williams, entretanto, as promessas tecidas, sobretudo, no Plano Marshall nunca foram, de fato, direcionadas a Moscou, de modo que a recusa soviética em compactuar com as condições impostas pela Casa Branca em troca de ajuda econômica foi um alívio para os norte-americanos, que, caso contrário, teriam de sentar à mesa de negociações e ouvir a voz do Kremlin. Da perspectiva soviética, por sua vez, a aceitação das condições previstas no Plano Marshall colocaria nas mãos dos Estados Unidos o poder de ingerência em assuntos internos da União Soviética (incluindo-se aí o poder de controlar orçamentos e definir prioridades de investimento estatal), assim como a capacidade de influenciar a política externa de Moscou.

Williams sustentou que, antes mesmo de entrarem na guerra contra o Terceiro Reich, os Estados Unidos já vislumbravam a possibilidade de emergir do conflito em condições de expandir e consolidar a Open Door Policy, por meio de um acordo com a Grã-Bretanha para policiar o mundo e impedir o surgimento de outras ameaças à ordem internacional. Assim, a supremacia da Open Door como estratégia, por excelência, da política externa dos Estados Unidos foi reafirmada, ao longo da década de 1940, como o principal norteador dos policymakers norte-americanos, que a justificavam em nome do interesse numa "prolongada era de paz, de hegemonia Anglo-Americana nas Nações Unidas e no mundo em geral, de livre comércio fora da órbita soviética e de uma liberalização gradual [do comércio] no interior [da órbita soviética]" (WILLIAMS, 1959, p. 139). Portanto, a reafirmação da Open Door, na década de 1940, como a chave para uma "era prolongada de paz" mundial marcou a maturidade da concepção de um "American century" da fronteira norte-americana pelo mundo, sustentada por uma onipotência virtuosa dos Estados Unidos, que se apresentavam então como os defensores da democracia.

Ainda que revestida por argumentos ideológicos, a essência da Open Door Policy foi integralmente mantida na década de 1940: para os Estados Unidos, a expansão econômica continuava sendo vista como uma necessidade para preservar a democracia e a prosperidade dentro de casa. Ao sustentar essa visão, os norte-americanos se recusavam a impor qualquer limite à expansão de suas fronteiras pelo mundo. Exatamente por essa razão, de acordo com Williams, Washington se recusou persistentemente a aceitar, entre 1941 e 1942, qualquer acordo proposto pelos soviéticos em relação às fronteiras da Europa Oriental.

Antes mesmo do final da Segunda Guerra, os soviéticos desejavam assegurar que as fronteiras do Leste Europeu fossem restabelecidas segundo a divisão territorial que vigorava antes da invasão nazista. Assim, entre 1941 e 1942, Stalin buscou reiteradamente junto aos aliados ocidentais apoio para 
um acordo sobre a Europa que fosse implementado no pós-guerra. Williams destacou que as propostas soviéticas concentravam-se em cinco questões: (i) as fronteiras soviéticas deveriam ser restauradas em conformidade com a sua configuração anterior à invasão nazista em 1941 (incluindo-se aí o respeito à chamada "Linha Curzon", acordada ao final da Primeira Guerra Mundial para estabelecer os limites entre a Polônia e a URSS); (ii) a Áustria deveria se tornar novamente um país independente; (iii) as bases industriais e militares da Alemanha deveriam ser desmanteladas; (iv) a Iugoslávia e a Albânia deveriam se tornar países independentes, assim como as fronteiras da Tchecoslováquia e da Grécia deveriam ser respeitadas; (v) e, por fim, a União Soviética deveria receber reparações de guerra da Alemanha.

As demandas soviéticas apresentadas entre 1941 e 1942, na realidade, foram mantidas mesmo após a Segunda Guerra Mundial. Contudo, a resposta dos Estados Unidos foi um uníssono "não" a qualquer proposta que atasse Washington a um acordo permanente com Moscou e que limitasse os interesses norte-americanos na Europa Oriental. Williams argumentou que os norteamericanos não desejavam assumir qualquer compromisso até que alcançassem uma posição de negociação claramente mais favorável aos Estados Unidos e eles acreditavam que essa posição só seria alcançada ao final da guerra, quando o Exército Vermelho não fosse mais decisivo na guerra contra Hitler.

Portanto, a grande ironia, do ponto de vista histórico, é que, embora estivessem relutantes em selar qualquer acordo com a União Soviética sobre o futuro da Europa antes do fim da Segunda Guerra Mundial, os Estados Unidos não podiam abrir mão do apoio soviético na guerra contra a Alemanha. Pois, se a política externa de Washington continuava, como propõe Williams, centralmente comprometida com a Open Door Policy, não poderia reconhecer quaisquer limites à expansão das fronteiras norte-americanas, fossem eles limites impostos pelo expansionismo desenfreado do Terceiro Reich ou pelos interesses soviéticos no Leste Europeu.

De acordo com Williams, Stalin acreditava que a prioridade da política externa soviética no pós-guerra deveria ser a formação de um perímetro de segurança para garantir que a União Soviética não fosse invadida precisamente num período de enorme fragilidade. Os custos da reconstrução, por sua vez, ficariam ao encargo daqueles que causaram a devastação: os alemães teriam de arcar com reparações de guerra, de modo que Moscou tivesse os recursos necessários para se reerguer. Stalin tinha em vista que, para alcançar esses objetivos, seria fundamental algum entendimento com os Estados Unidos, de modo que, antes mesmo do fim da Segunda Guerra Mundial, o Kremlin estava seriamente comprometido em evitar a disseminação de revoluções comunistas pelo mundo, de tal forma a não confrontar os interesses norteamericanos. Para o líder soviético, se uma política de coexistência com os norte-americanos fosse bem-sucedida, então a União Soviética ganharia o 
tempo e os recursos necessários para se recuperar da guerra e o comunismo se disseminaria lentamente pelo mundo (sobretudo pelos países periféricos não industrializados) sem ser visto pelos Estados Unidos como uma ameaça. Como sintetizou Williams:

Como Stalin deixou claro no inverno de 1941-1942, a União Soviética pretendia inteiramente restabelecer o que considerava ser as suas fronteiras naturais e desejáveis no Leste Europeu. Ele também concluiu que os Estados Unidos e a Inglaterra também ofereceriam resistência a esse propósito. A oposição [norte-americana e inglesa] levantou na mente dos líderes soviéticos a questão muito natural se eles precisariam ou não de um perímetro de segurança ainda mais forte. (WILLIAMS, 1959, p. 145, tradução do autor)

Entre 1942 e 1943, mesmo diante da persistente recusa dos Estados Unidos em reconhecer os interesses soviéticos e de negociar qualquer acordo permanente com Moscou, Stalin se manteve firme no propósito de pressionar os Aliados ocidentais por compromissos que assegurassem aos soviéticos o tão desejado perímetro de segurança no pós-guerra. Assim, mesmo sinalizações vagas de que os Estados Unidos apoiariam a reconstrução soviética eram bem recebidas, ainda que com descrença, pelo Kremlin.

Em fevereiro de 1945, em Ialta, Churchill e Roosevelt reconheciam o empenho de Stalin em respeitar os acordos firmados no decurso da Segunda Guerra. Os Estados Unidos reconheciam igualmente que os líderes comunistas chineses estavam cada vez mais inclinados a negociar com os norte-americanos sobre o futuro da China, num claro sinal de que a decisão de Moscou de não apoiar revoluções mundo afora não agradava a Pequim. Portanto, segundo Williams, em Ialta os Estados Unidos estavam em clara posição de vantagem, fosse do ponto de vista político, fosse da perspectiva econômica, para negociar um acordo com os soviéticos. Ainda assim, Washington se recusava a abandonar a sua tradicional estratégia expansionista, o que implicava mais uma vez a impossibilidade de reconhecer qualquer limite à Open Door e, portanto, a inviabilidade de assegurar ao Kremlin o seu perímetro de segurança.

O adensamento dos antagonismos entre os Estados Unidos e a União Soviética em Ialta, em 1945, era, na interpretação revisionista, o resultado de interesses distintos e conflitantes. De um lado, Washington professava mais uma vez a sua crença na Open Door Policy como o caminho para evitar uma nova depressão e, portanto, não poderia reconhecer qualquer limite à expansão da fronteira econômica norte-americana. Washington ainda acreditava que a devastação econômica soviética forçaria o Kremlin a ceder aos interesses norteamericanos, o que facilitaria sensivelmente a reorganização do mundo segundo os princípios da Open Door. A União Soviética, por outro lado, desejava sair 
de Ialta com uma garantia de que teria os recursos necessários para bancar a sua dispendiosa reconstrução, fossem esses recursos assegurados por um empréstimo norte-americano (algo com que Stalin já não contava em 1945) ou por reparações de guerra obtidas da Alemanha. Igualmente importante para o Kremlin era um acordo que garantisse o perímetro de segurança soviético ao longo do Leste Europeu, do Mar Negro e do Oriente Médio, algo sabidamente mais difícil de alcançar diante da animosidade dos Estados Unidos.

Williams sustentou que, mesmo após a frustração em Ialta, Stalin manteve-se fiel a uma abordagem conservadora em política externa, buscando algum "modus vivendi com os Estados Unidos, [para] então se concentrar na recuperação e no desenvolvimento internos" (WILLIAMS, 1959, p. 153). Uma sinalização clara dessa abordagem foi a política externa conduzida pelos soviéticos no Leste Europeu logo após a derrota dos nazistas. Stalin não se isentou, por certo, de reafirmar os interesses do Kremlin na região, mas tampouco se engajou na promoção de revoluções comunistas, incentivando, alternativamente, a formação de governos de coalizão interna com partidos alinhados à União Soviética e mesmo com lideranças políticas reticentes da influência de Moscou.

Williams concluiu a sua detalhada análise das relações entre os Estados Unidos e a União Soviética na década de 1940 reafirmando três teses centrais à abordagem revisionista:

(...) as decisões soviéticas de 1944 a 1947 foram baseadas nas condições domésticas russas; segundo, (...) os Soviéticos estavam assumindo que o capitalismo se estabilizaria ao redor do grande e inabalável poder dos Estados Unidos; e terceiro (...) esses dois fatores apontavam na cabeça de vários russos - incluindo Stalin - a necessidade de alcançar alguma forma de acordo com os Estados Unidos. (WILLIAMS, 1959, p. 155, tradução do autor)

Portanto, na interpretação defendida por Williams, "a Open Door Policy evoluiu para um aparato crescentemente agressivo de poder global como um modo de preservação do império norte-americano" (WILLIAMS, 1959, p. 156). Foi exatamente nesse processo de consolidação da Open Door que Williams identificou a origem da chamada "tragédia da diplomacia americana". 
IV. A tragégia da diplomacia americana:a Open Door Policy como ameaça à democracia

A interpretação historiográfica defendida por Williams não apenas estabeleceu um vínculo direto entre a política interna e a política externa norte-americana, identificando na "frontier thesis" a ideologia de preservação da democracia e da prosperidade dentro dos Estados Unidos, mas também relacionou historicamente a Open Door Policy a uma série de conflitos e antagonismos decorrentes da defesa dos interesses imperialistas norteamericanos. Portanto, na perspectiva revisionista, a cristalização dos antagonismos entre soviéticos e norte-americanos - desde as disputas pela abertura dos mercados asiáticos no século XIX até a recusa em reconhecer limites à fronteira norte-americana no mundo após a Segunda Guerra Mundialé consequência direta da política externa expansionista, imperialista e agressiva conduzida pelos Estados Unidos.

Williams concluiu, em seu The Tragedy of American Diplomacy, que a Open Door Policy, comprometida por princípio com a reprodução da democracia e da prosperidade dos Estados Unidos, levou à persistente violação de tradicionais ideais de liberdade e de autodeterminação dos povos - ideais que estão, eles mesmos, na origem histórica da democracia estadunidense. Assim, ao violar a liberdade e o direito à autodeterminação de vários povos na busca pela reafirmação de seus interesses expansionistas, os Estados Unidos traíram e abandonaram os princípios mais elementares da democracia estadunidense, o que é, para Williams, a "tragédia da diplomacia americana".

A resistência dos Estados Unidos, após a Segunda Guerra Mundial, contra movimentos revolucionários percebidos como uma ameaça à organização mundial segundo os princípios da Open Door implicava, conforme Williams, uma política externa cada vez mais agressiva e intervencionista, com consequências cada vez mais danosas para a própria sociedade norte-americana.

Em 1972, ao preparar uma reedição de The Tragedy, Williams observou que o amplo movimento doméstico de oposição à Guerra do Vietnã, nas décadas de 1960 e 1970, decorria precisamente da percepção das consequências deletérias da política externa conduzida por Washington para a própria sociedade estadunidense: a redução da capacidade de autodeterminação individual, diante da forte repreensão doméstica às dissidências; a redução da capacidade individual de se perceber como parte de uma comunidade, que decorria de uma poderosa manipulação da sociedade pelo Estado; e, por fim, o acentuado declínio do comprometimento dos Estados Unidos com uma conduta moral. O reconhecimento social dessas consequências difundiu-se rapidamente nos Estados Unidos e em outros países durante a desastrosa intervenção na Indochina, levando à "convicção de que a sociedade norte-americana existente tinha de ser mudada" (WILLIAMS, 1959, p. 157).

Williams defendeu, assim, que a oposição interna à Guerra do Vietnã 
despertou, nos Estados Unidos, um legítimo movimento social que acreditava na necessidade e na premência de uma profunda transformação da política externa e da sociedade norte-americanas. Nesse sentido, a Guerra Vietnã, vista pelo autor como uma radicalização da Open Door, contribuiu de forma central para o questionamento dos pilares nos quais estava assentada a política externa conduzida pelos Estados Unidos desde o final do século XIX.

$\mathrm{O}$ aumento da oposição doméstica à política externa norte-americana e o próprio questionamento de crenças sobre o papel dos Estados Unidos no mundo forçaram a mobilização dos líderes políticos. Num primeiro momento, mesmo diante da proliferação de dissidências, Washington insistiu na retórica salvacionista da guerra, defendendo a intervenção no Vietnã como um meio para garantir a paz e a liberdade mundiais. Porém, diante do adensamento de uma resistência social que não enxergava a Open Door como uma estratégia de reprodução da democracia e da prosperidade, as lideranças foram forçadas a agir. Primeiro, com a retirada da candidatura do presidente Lyndon Johnson, em 1968. Depois, com a tentativa de Richard Nixon de "estabilizar o império existente reduzindo as perdas no Vietnã e negociando um modus vivendi interino com a Rússia, com a República Popular da China e com vários outros governos revolucionários" durante a détente (WILLIAMS, 1959, p. 158)9.

Face às consequências inexoráveis de uma política expansionista que se voltara contra os próprios princípios democráticos com os quais deveria estar, em tese, comprometida, Williams propôs um conjunto de mudanças para a política externa norte-americana, que o próprio autor classificou como "radicais". Para o autor, os Estados Unidos deveriam reconhecer primordialmente que a democracia e a prosperidade de sua sociedade não dependiam necessariamente de uma fronteira econômica em expansão. Esse reconhecimento permitiria a Washington abdicar de sua política comercial agressiva e "parar de definir o comércio como o controle de mercados para os nossos produtos excedentes e como o controle de matérias-primas para as nossas fábricas" (WILLIAMS, 1959, p. 158). Esse seria o primeiro passo para transformar a estratégia, muito empregada pelos Estados Unidos, de usar o comércio exterior como uma arma contra aqueles que se opunham aos interesses norte-americanos, transformando-o alternativamente num meio para reduzir tensões com outros países.

Em segundo lugar, observou Williams, seria fundamental para os Estados Unidos o reconhecimento de que a União Soviética e os outros países comunistas não eram a origem de todo o mal. Nesse sentido, caberia aos Estados Unidos "adotar um programa que encoraje e permita aos países comunistas se moverem na direção da sua própria visão utópica de uma boa sociedade, enquanto nós nos esforçamos para seguir o caminho de acordo com nossos próprios ideais" (WILLIAMS, 1959, p. 159). Se os Estados Unidos fossem capazes de reconhecer a legitimidade de formas distintas de organização 
social, então poderiam também reconhecer que a política externa soviética era primordialmente defensiva, o que abriria uma brecha para negociações com Moscou para interromper a desenfreada corrida armamentista que marcou a Guerra Fria.

Williams argumentou que mudanças na política externa norte-americana eram igualmente vitais para permitir que os Estados Unidos se concentrassem na transformação da sua própria sociedade, que, na interpretação do autor, era fortemente penalizada pelos problemas engendrados pela Open Door. Ao mesmo tempo, uma reordenação social interna, radicada no reconhecimento das consequências negativas da política externa expansionista, abriria aos Estados Unidos a possibilidade de construir uma "open door for revolutions" (WILLIAMS, 1959, p. 159). Na interpretação de Williams, os Estados Unidos deveriam se comprometer com uma política externa que apoiasse as revoluções e as transformações sociais desejadas por cada povo, fossem essas revoluções comunistas ou não. Somente uma política de "portas abertas para as revoluções" estaria legitimamente comprometida com a liberdade de cada país para escolher a sua própria forma de organização social, política e econômica.

Williams concluiu a sua crítica destacando uma ironia encerrada pela sua reinterpretação sobre a Open Door Policy. Segundo o autor, a interpretação revisionista está fundamentada numa perspectiva "radical" porque não apenas se propõe a analisar e a repensar as características e a lógica da política externa norte-americana desde 1890, mas também porque leva à conclusão de que tal política deveria ser transformada em sua essência se os Estados Unidos de fato desejassem reproduzir, no longo prazo, a sua democracia e a sua prosperidade. Nesse sentido, ironicamente, a Open Door Policy se transformou, na interpretação revisionista, numa força antidemocrática, voltando-se precisamente contra aquilo que, em tese, deveria defender. Assim, observou o autor:

(...) a democracia e a prosperidade [dos Estados Unidos] dependem da definição da Nova Fronteira (...) para significar a aceitação de limites sobre a liberdade de ação dos Estados Unidos. (...) Se os Estados Unidos não puderem aceitar a existência de tais limites sem abrir mão da democracia e não puderem proceder para aperfeiçoar e ampliar a democracia dentro de tais limites, então o esforço tradicional para sustentar a democracia através da expansão levará à destruição da democracia. (WILLIAMS, 1959, p. 161 , tradução do autor)

A interpretação de Williams, como observado, subverteu a explicação ortodoxa sobre a política externa norte-americana, propondo uma visão radicalmente distinta sobre os interesses, as motivações e os meios empregados 
pelos Estados Unidos em suas políticas com o resto do mundo desde o final do século XIX. A tese de que os Estados Unidos se voltaram contra os princípios democráticos em nome da defesa da própria democracia marcou uma inflexão na historiografia sobre a Guerra Fria. De um lado, a identificação de antagonismos entre russos e norte-americanos já ao final do século XIX colocava em questão a periodização ortodoxa sobre a origem da Guerra Fria. Por outro, a identificação da política externa norte-americana expansionista, imperialista e agressiva como a principal catalisadora dos antagonismos que selaram a polarização entre os Estados Unidos e a União Soviética na década de 1940 chocava-se frontalmente com a tese ortodoxa de que a União Soviética era a principal, senão a única, responsável pela Guerra Fria.

A interpretação proposta por Williams foi o estopim para um longo debate revisionista sobre a Guerra Fria, que se voltou para o questionamento de suas origens e para a análise de suas consequências. O resgate do pensamento de Williams é, portanto, de especial relevância para a análise historiográfica sobre a Guerra Fria, sobretudo num contexto de reconstrução de uma memória predominante - ou hegemônica - sobre aquele período.

\section{Considerações finais: críticas ao revisionismo}

As propostas "radicais" defendidas Williams para a política externa norte-americana não lograram o sucesso político pretendido pelo autor, mas revolucionaram o debate sobre a Guerra Fria no campo historiográfico. A corrente historiográfica pós-revisionista, como o próprio nome sugere, inseriuse precisamente no debate suscitado pelas teses revisionistas originalmente concebidas por Williams. Embora o objetivo central do artigo não vislumbre uma discussão detalhada das contestações ao Revisionismo, é relevante introduzir as principais críticas às teses de Williams, sobretudo diante do protagonismo conquistado pelo pós-revisionismo no debate historiográfico sobre a Guerra Fria.

John Lewis Gaddis, “pai” do pós-revisionismo, definiu essa corrente historiográfica como "um novo consenso que se baseia tanto na interpretação tradicionalista [ortodoxa] quanto na interpretação revisionista para apresentar uma explicação mais balanceada sobre o começo da Guerra Fria" (WALKER, 1981, p. 207 apud GADDIS, 1983, p. 172) $)^{10}$. Não obstante a abordagem pluralista e balanceada originalmente pretendida, Gaddis adotou, em obras posteriores, uma visão fortemente alinhada à corrente ortodoxa, baseada num conjunto de críticas às teses revisionistas, que podem ser sintetizadas em quatro grandes contestações.

Gaddis contestou, originalmente, a tese, supostamente defendida pelos revisionistas ${ }^{11}$, que identificava nas necessidades de reprodução do capital norte-americano as razões para a expansão do poder do "império americano" após a Segunda Guerra Mundial. Segundo o autor, estudos pós-revisionistas, 
conduzidos com base na pesquisa de novas fontes, concluíram que "há pouca evidência de que eles [os policymakers dos Estados Unidos] viam uma crise do capitalismo como a questão mais urgente encarada pelo país ao final da Segunda Guerra Mundial" (GADDIS, 1983, p. 173).

Gaddis argumentou também que a tese revisionista de que, após a 1945, a União Soviética estava centralmente preocupada com a manutenção de sua segurança e disposta a cooperar com os Estados Unidos para alcançar esse objetivo era não apenas falaciosa, mas baseada "na fé, não em pesquisa" (GADDIS, 1983, p. 175). O autor sustentou, assim, que os revisionistas simplesmente tomavam como pressuposto a disposição de Stalin de cooperar com os Estados Unidos, em oposição à intransigência norte-americana diante dos interesses de expansão econômica que, supostamente, motivavam a política externa de Washington. Para Gaddis, ao contrário, "a causa fundamental da Guerra Fria foi a ambição doentia de Stalin, a sua determinação em buscar segurança de tal modo que restava pouca ou nenhuma segurança para os demais atores da arena internacional" (GADDIS, 1983, p. 176).

A terceira tese atribuída ao revisionismo e contestada por Gaddis se refere à imposição coercitiva do "império americano" após a Segunda Guerra Mundial, por meio de alianças militares e de relações de dependência econômica. Gaddis contrapôs a essa tese a ideia de que o poder exercido pelos Estados Unidos na Guerra Fria era primordialmente consensual e, em grande medida, o "império americano" era bem vindo e até mesmo desejado pelos países sob a influência de Washington. Contrariando os argumentos atribuídos aos revisionistas, Gaddis defendeu que "que a esfera de influência norte-americana surgiu muito mais a convite do que por imposição" (GADDIS, 1983, p. 177).

Por fim, Gaddis contestou a tese, novamente atribuída ao revisionismo, de que a expansão do poder dos Estados Unidos ocorreu contra a vontade do povo norte-americano, que teria sido manipulado, com base no mito do perigo representado pelo comunismo, para dar suporte à política externa conduzida pela Casa Branca.

Em relação à última crítica introduzida por Gaddis, é fundamental esclarecer que não existe, na literatura desenvolvida pelos autores revisionistas, uma só indicação que comprove que o revisionismo defendia essa interpretação do modo como ela é apresentada por Gaddis. Ao contrário, há um grande esforço dentro da corrente revisionista para elucidar as ligações entre a política externa conduzida pelos Estados Unidos durante a Guerra Fria e os seus determinantes domésticos. Gaddis, na realidade, associou a tese em questão ao revisionismo na tentativa de colocar em questionamento o próprio contexto histórico no qual as ideias revisionistas floresceram. Nesse sentido, do ponto de vista pós-revisionista, caberia mesmo indagar se os movimentos de contestação da política externa norte-americana que se adensaram a partir década de 1960 
(dentre os quais, o revisionismo) eram expressão legítima da vontade do povo norte-americano, ou, ao contrário, se expressavam o ponto de vista de uma minoria, não representativa da sociedade norte-americana, que não apoiava a política conduzida por Washington.

Essas breves considerações, longe de esgotar o intenso debate entre o revisionismo e o pós-revisionismo, são apenas uma indicação das importantes transformações que as ideias de Williams introduziram na historiografia sobre a Guerra Fria. A retomada da interpretação revisionista faz-se ainda mais premente no contexto de um debate historiográfico em que o pós-revisionismo, embora expressão da velha ortodoxia, ainda é a corrente mais ressonante.

\section{Notas}

1 Uma análise das três principais correntes historiográficas dedicadas à Guerra Fria (ortodoxia, revisionismo e pós-revisionismo) pode ser encontrada em: MUNHOZ, Sidnei J. Guerra Fria: um debate interpretativo. In: TEIXEIRA DA SILVA, Francisco Carlos. O século sombrio: uma história geral do século XX. Rio de Janeiro: Campus, 2004[a]; e MOURA, Gerson. Historiografia e relações internacionais. In: Contexto Internacional, n. 10, jul. 1989.

2 A corrente historiográfica revisionista sobre a Guerra Fria englobou um conjunto muito amplo de historiadores. Além de Williams, destaque também para Walter LaFeber, Gar Alperovitz, Gabriel Kolko, Joyce Kolko e Lloyd C. Gardner.

3 WILLIAMS, William Appleman. The Tragedy of American Diplomacy. New York: Norton, 1988 (reedição da primeira versão, publicada em 1959).

4 WILLIAMS, William Appleman. The frontier thesis and American foreign policy. In: Pacific Historical Review, XXIV, November 1955.

5 TURNER, Frederick Jackson. The significance of the frontier in American History. New York: Nabu Press, 2011 (reedição do original de 1893).

6 ADAMS, Brooks. The law of civilization and decay: an essay on history. New York: Kessinger Publishing, 2010 (reedição do original de 1895).

7 As teses centrais da Doutrina de Contenção do Comunismo foram desenvolvidas e analisadas em: (a) KENNAN, George Frost. Soviet Foreign Policy, 1917-1941. Londres: Van Norstrand, 1960; (b) KENNAN, George Frost. The Long Telegram. In: Harry S. Truman Library and Museum, February 22, 1946. Acesso: 26/04/2016. Disponível em: http://goo.gl/8eU1kl; (c) KENNAN, George Frost. The Sources of Soviet Conduct. In: Foreign Affairs, July 1st. 1947.

8 A ideia do "american century" foi analisada em detalhes por LAFEBER, Walter. The American Age. United States Foreign Policy at Home and Abroad since 1750. New York: Norton \& Company, 1989, $1^{\text {a }}$ ed.

9 Uma análise sobre a détente, as suas origens e consequências foi desenvolvida por: MUNHOZ, Sidnei J.; ROLLO, José Henrique. Détente. In: Dicionário do Século XX: guerras e revoluções. Rio de Janeiro: Campus, 2004[b].

10 GADDIS, John Lewis. The emerging post-revisionist synthesis on the origins of the Cold War. In: Diplomatic History, vol. 7, issue 3, p. 171-190, July 1983.

11 É fundamental diferenciar as teses revisionistas da interpretação de Gaddis sobre essas 
teses. O autor, no anseio de refutar a interpretação revisionista sobre a Guerra Fria, incorreu em diversas imprecisões e erros grosseiros sobre as teses seminais defendidas por Williams.

Artigo recebido em novembro de 2016. Aceito em dezembro de 2016. 